\title{
Research on the Current Situation and Development of Community E-commerce
}

\author{
Ting Wang ${ }^{1,2, a}$ Zhenlong Peng ${ }^{1,2,, b,}$ Zhenwei Zhang ${ }^{1,2, c}$ \\ ${ }^{1}$ TSL Business School of Quanzhou Normal University \\ Quanzhou 362000, China \\ ${ }^{2}$ High Educational Engineering Research Center of Fujian Province for E-Commerce Intelligent \\ Based on Cloud Computing and Internet of Things \\ Quanzhou 362000, China \\ *Corresponding author
}

\begin{abstract}
With the continuous development of social media, the economic form based on social relationships has developed rapidly, and network red economy and fan economy have developed rapidly. This paper expounds the basic concepts of community e-commerce and the development trend of ecommerce in China, and analyzes the advantages and disadvantages of community e-commerce. In particular, it summarizes the problems existing in brand building, fan maintenance, operation and consumption habits during the development of community e-commerce, and proposes solutions to related problems in terms of building cultural systems, product positioning, and operational skills. It has seized the mainstream development direction of community e-commerce economy and provided relevant research directions for relevant practitioners.
\end{abstract}

Keywords-Community; E-commerce; Community construct; Community culture

\section{INTRODUCTION}

\section{A. The concept of community}

The community is based on the Internet and is based on certain characteristics such as interest preferences, status, career, aesthetics and values of life. For example, the people who like finance maybe construct a community. The boss may be in a community, and people who like skiing will be in a community. In business, the community has an important meaning. The resulting business behavior is community marketing, and community marketing realizes the commercial value of the community [1]. The deep communication between enterprises and users is to turn users into fans. Fans are a group of people who are interested in a certain person or theme. They are a group of consumers who are interested in a certain scheme. Community operations have become one of the important business models of this era. The community is an important interpersonal relationship circle in the moment. How to maximize its business value, how to find potential operational targets, and realize the business closure and the fission of marketing [2] is an important issue for enterprise development.

\section{B. Community e-commerce and its main characteristics}

The community is not a novel concept. There is a proverb in China- "things are gathered together and people are divided into groups." The social economy actually has a relatively solid sociological foundation. It's just that before the advent of the mobile Internet era, the cost of interaction within the community is too high and too inefficient, which makes it difficult to uncover the true value of the social economy. With the increasing number of social networking software based on mobile dating, they occupy the most fragmentation time of people, and also provide a new channel for e-commerce to interact with consumers, and at the same time shorten the gap between enterprises and consumers. Internet technology has made it easier to bring together a group of people, and maintaining these people and marketing them in an appropriate way constitutes a community e-commerce. The business model of the foreign iPhone is the fan economy. The domestic "XiaoMi" technology is also based on the emotional recognition of the brand. From the QQ community to Weibo to WeChat, to the recent "live platform", the diversified expressions of social groups, the trend of the development of community e-commerce has become more apparent. They have the following characteristics.

\section{1) Targeted and interactive}

The targeting of community e-commerce is based on the positioning of the community itself. Fan groups have their own personal tags. Through these tags, community sellers can guarantee a more detailed investigation and understanding of the community groups they are affiliated with. the company considers consumers' various unique preferences and needs etc., and develop and launch products suitable for them, and on the other hand, consumers according to their personality traits For the degree of acceptance of the price and expectations of the product, you can choose a precise community. Through multiple layers of screening, community sellers and consumers can find their own community targeting. They communicate feelings and information through multiple interactions. 


\section{2) Emotionalization and profitability}

The community allows a group of people with common values and the same interest to establish mutual trust and emotional relationships, but at the same time, in order to maintain the normal operation of the community, most individuals in the system need to produce value and gain.

\section{3) Self-replication and evolution}

The community itself has self-growth and self-replication capabilities. After some sub-themes, it can be split into more thematic communities. At the same time, community members should have the ability to self-evolve. The well-run community will keep changing, continuously optimizing, and more focusing on a product, service or technology according to the actual situation.

\section{THE DEVELOPMENT MODEL OF COMMUNITY E- COMMERCE}

\section{A. Virtual community development model}

A virtual community is built for a certain topic based on social software such as QQ and WeChat . At the end of 2017, the number of monthly active users of QQ and WeChat reached 780 million and 990 million respectively. In the internal development of the community, there is a relatively fixed model. The community is organized from members, active interaction, reasonable operation, and commercialization. In this model development, the community has also completed branding and specialization from simple group

\section{B. Fan-driven development model}

A celebrity will attract a large number of followers because of his social influence. These followers are his fans. The words and deeds of bloggers often influence the consumption behavior of fans to a large extent. In terms of commercialization, bloggers can use the original blog post to create and publish circles, and through the advertising, endorsement and other forms to show fans, which is also known as the fan economy. They can even achieve more commercial value through membership, branding, platform building and new models of derivatives.

\section{Business model based on live broadcast}

With the popularity of $4 \mathrm{G}$ networks and the development of future $5 \mathrm{G}$ networks, data communication is faster and traffic costs are lower. Therefore, live broadcasting has become an important social marketing model. According to the user survey data, users with consumer purpose when watching live broadcasts are more inclined to pay attention to "live + " mode advertisements composed of content marketing, interactive marketing and e-commerce live broadcast. The live broadcast platform uses virtual currency to open purchase channels. Increase the conversion rate of items and attract fans to use virtual currency to reward. In 2018, the live broadcast platform represented by fighting fish and quick hands is developing rapidly. In the future, image recognition and speech recognition will become the focus of intelligent live broadcast technology, aiming at providing users with better scene experience and creating better for advertisers. Marketing environment.

\section{THE DEVELOPMENT DILEMMA OF COMMUNITY E- COMMERCE}

\section{A. Difficulties in shaping community brand}

Community brands are a status symbol for community fans, and the popularity of community brands determines the loyalty of community fans to the community. The shaping of community brands is extremely difficult [5]. Most of the community e-commerce are unknown brands, which limits the expansion of the community. On the other hand, the brand determines the survival time of the community. If the community e-commerce cannot expand the popularity of the community brand. It's hard to increase community visibility, which leads to more fan loss than attention.

\section{B. Maintenance difficulties of fan traffic}

For a community, fans are the cornerstone of a community. A community without loyal fans is like a pool of dead water that cannot function well. The maintenance of community fans is a pain point for community e-commerce. Community fans are attracted by community topics or products, but if community content or products are not attractive enough, community fans have a poor consumer experience, which will possiblely cause a large loss of fans. This has a huge negative impact on the normal operation of the entire community [6]. If the negative emotions in the community are not handled properly, it is easy to form a viral spread, and it is difficult to reverse the first impression of others on the community, which is not conducive to expanding the influence of the community e-commerce.

\section{Excessive operating costs}

Whether it is for sellers or platforms, they need to invest more in e-commerce. Whether it is IT development and maintenance, traffic acquisition, logistics and services, etc., it requires a lot of capital investment [7]. Many communities often underestimate the operational difficulty and input costs of e-commerce. Especially the difficulties encountered in operation are more difficult than the integrated e-commerce. On the one hand, no matter which category, community ecommerce will inevitably have a certain competitive relationship with various types of integrated e-commerce platforms such as Tmall and JD. Compared with the integrated e-commerce, the community e-commerce is small, and their voice in the supply chain will inevitably be lower. In terms of the price of goods, the collection cycle, and the supply guarantee of the goods, the community e-commerce has no advantage, so it is difficult to reflect the characteristics of the goods. On the other hand, e-commerce platforms are increasingly aware of the importance of content, and have taken actions. For example, Ali launched Taobao headlines, live video, main content e-commerce, and recruited a large number of net red to provide traffic support. Jingdong launched the Jingzhi wardrobe and Mamabang. They launched a baby growth plan to bring in users through the content, thus cutting into the social economy and the traffic of the community ecommerce is constantly being eroded. 


\section{Difficulties for users to form consumption habits}

In online consumption, it is easy for consumers to consume shopping based on cost performance. They are no longer limited to the same store, and when the same product has lower prices in other stores, it is difficult for consumers to buy products with higher prices. Users' consumption habits are difficult to change in a short period of time. It is an urgent task for community e-commerce to let consumers have a sense of identity, gain a sense of identity and differentiate themselves from other products [8]. Otherwise, the conversion rate may be much lower than expected.

\section{SUGGESTIONS FOR THE DEVELOPMENT OF COMMUNITY E-COMMERCE}

There are some problems behind the booming of community e-commerce. Below I have put forward a few points of view, we believe that community e-commerce can get better development after solving these problems.

\section{A. Pay attention to the diversification of community}

At present, with the rapid development of the community, its own form is more diverse, the industries involved are more abundant, and the cooperation and integration between industries is further deepened. The community has a large space for development in content, hardware, data mining, payment and finance. At the same time, the social economy has also produced more emerging models due to the increase in industrial links [9]. Subsequent project incubation, crowdfunding, crowdsourcing, information docking and indepth cooperation will become new opportunities.

\section{B. Building a community culture system}

The most important thing for a community is culture. Building a cultural system is tantamount to building the purpose of the community. Community culture includes goals, values, and community conventions. Community members need to do something together to deepen their sense of identity with the brand community. With a common culture and goals, continuous community marketing can really produce results [10]. Common goals and values can enhance the emotional links between members. Let simple relationships become friends. So the recognition of culture is the foundation of social marketing. After building a cultural system, consumer followup is an inevitable behavior. Social marketing only continually outputs a sense of belonging to members, and members will become sticky and spontaneously spread the community culture.

\section{Cultivating community e-commerce operation talents}

Social entrepreneurs need to be updated in terms of concepts, knowledge, and ideas. Social e-commerce merchants need not only the e-commerce technology foundation, operation management and other capabilities, but also the ability of community content creation and language expression. At the same time, they are able to accurately analyze hot search sensitive words, to explore and process new topics, and may also to process image. They are able to complete the quality of the community's content and maintain loyal fans, attract new fans [11], etc., to promote the healthy operation of the community.

\section{Accurate positioning of community products}

A community always has to remember its own position: to solve the painful points for fans to retain fans, if a community simply promotes its own products, the community will decline. If community products are too broad, it will definitely make the community mixed. Regardless of the level of service that a community's end-service customers are, community products will eventually tend to be small and beautiful communitybranded products. The more accurate the positioning of the community products, the more you can get the recognition of the fans, and the distance from the community fans. Among the community e-commerce, the smaller and more beautiful products are more easily accepted by fans.

\section{E. Pay attention to the scene of community service}

For social service providers, the service platform not only provides the community with a single-link service to meet its needs, but also provides integrated operations and customized services for multiple platforms. In the future, the community service platform will develop more targeted and personalized service solutions at all stages of community development. From community entry to communication platform application to marketing, the community will be packaged and operated as a brand. Provide full case planning; at the same time, the service platform will provide more expandable services in combination with other business characteristics, and provide marketing solutions and business realization models that are closer to life scenarios and product usage scenarios, and provide more for the community economy to further explore.

\section{SUMMARY}

The community e-commerce conforms to the trend of the times and is a new business model with long-term stability and explosive growth. Behind the community is not just fans and interests, but also a complex business ecosystem. At this stage, its business ecology has not been fully constructed, and there are many difficulties and pain points need to resolve. Only by building a better community culture system, shaping the community brand, and building a more stable foundation can community e-commerce establish a more sustainable community relationship and trust based on community members, professionals, and operational talents. Promote products and services to community members. The essence of community e-commerce is to make good content on good products and attract more consumers to become fan groups. Only in this way can we build a better community e-commerce ecosystem.

\section{ACKNOWLEDGEMENT}

This work was partly supported by Key Projects of Science and Technology Plan in Fujian Province under Grant 2016H0029; Fujian Social Science Federation Project No.FJ2018B022; Key Projects of Quanzhou Technology Bureau Nos.2018C004, 2012Z102, 2013Z123; 


\section{REFERENCES}

[1] Zhang Yurong. Social e-commerce is not just for buying and selling [J]. Xiaokang, 2016, (28): 86-87.

[2] $\mathrm{Xu}$ Wei. Research on Business Model of E-commerce Enterprises under Community Logic $[\mathrm{J}]$. Journal of Shandong Institute of Business and Technology, 2016, 30(06): 79-85+92.

[3] Jubilee. Vertical E-commerce Path: The community is more than just a connection [J]. Business School, 2016, (06): 61-63.

[4] Yang Ying. Research on the relationship between shopping mall sharing user trust and online consumption willingness [D]. Central China Normal University, 2014.

[5] Wang Zhujun. Community Marketing in the Age of Fan Economy [J]. International Public Relations, 2016, (06): 60-67.

[6] Wu Tingting. Research on the Application of Community E-commerce in Cross-border E-commerce under the Background of Mobile Internet [J]. Modernization of Shopping Mall, 2017, (10): 15-17.

[7] Jia Yinfeng. Analysis and Countermeasure Research on the Dilemma of Self-operated Book Community E-commerce [J]. Publishing Wide Angle, 2017, (07): 14-15.

[8] Wang Jiawei, Li Yining. The core logic of brand community marketing in the social media era [J]. Contemporary Communication, 2014, (05): 93-95.

[9] Yan Wenbo, Li Wei. On the Mechanism and Trend of Mass Communication in Social Marketing [J]. Publishing Wide Angle, 2017, (08): 6-9.

[10] Su Yuting. Research on the influence mechanism of brand community perception and consumer involvement on brand community value [D]. Shandong University.

[11] Weishu $\mathrm{Hu}$, Zhiguo Gong, Leong Hou U, Jingzhi Guo. Identifying influential user communities on the social network[J]. Enterprise Information Systems,2015,9 (7). 